\title{
Cutaneous Manifestations of Thyroid Hormone Disorder
}

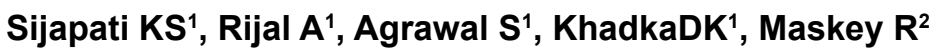

${ }^{1}$ Department of Dermatology and Venereology, ${ }^{2}$ Department of Internal Medicine, B.P Koirala Institute of Health Sciences (BPKIHS), Dharan, Nepal

\begin{abstract}
:
Introduction: Thyroid hormone disorder (THD), a major health problem, is associated with a wide range of diseases. One of the organs, which shows this wide range of clinical signs is the skin. Some dermatological findings may be the first symptoms of THD. Therefore, this study was planned to determine various cutaneous manifestations of THD that can be used as a diagnostic marker for THD. In Nepal due to lack of awareness, thyroid diseases may go unnoticed .So, cutaneous manifestations help in early diagnosis and treatment of THD.

Objectives: To identify cutaneous manifestations of THD and to evaluate dermatological manifestations specific for THD.

Materials and Methods: Seventy six patients with diagnosis of THD attending endocrine clinic of Internal Medicine Department in BPKIHS, Dharan were consecutively assessed for cutaneous changes by detailed history and clinical examination. As a control group, 26 age and sex matched individuals without THD were included to assess frequency of cutaneous manifestation in normal individuals.

Results: Fifty five $(72.3 \%)$ cases and $4(15.4 \%)$ control had skin changes. This observation was statistically significant with OR-14.4 (95\% Cl4.43 - 46.78) and p<0.001. Hair changes (OR-2.100, 95\% Cl 0.647-6.821 and $\mathrm{p}=0.210$ ) and nail changes (OR-1.818, 95\% $\mathrm{Cl} 0.371-8.902$ and $\mathrm{p}=0.726$ ) had no statistically significant association with THD.

Conclusion:THD may present as or be associated with many changes in skin, hair and nails.

Key words: Cutaneous changes; Hypothyroidism; Hyperthyroidism
\end{abstract}

\section{Introduction}

T hyroid hormone disorders (THD) are associated with a wide range of diseases. One of the organs which best shows the various clinical signs is the skin. ${ }^{1}$ Thyroid hormones are instrumental in regulating the health of skin so when the thyroid gland becomes underactive or overactive a variety of skin, hair and nail changes occur. The dermatological manifestation of hyperthyroidism include- warm, moist skin, diffuse non-scarring alopecia, palmo-plantar hyperhidrosis, facial flushing, skin pigmentation, pretibial myxedema, onycholysis, plummers nail etc and of hypothyroidism include - dry coarse skin, hair loss, pruritus, hypohydrosis, yellow skin, brittle nails, loss of cuticle, vertical striations etc. ${ }^{1}$

\footnotetext{
Address of Correspondence:

Dr. Karuna Singh Sijapati

Senior resident

Department of Dermatology and Venereology

BP Koirala Institute of Health Sciences, Dharan

E-mail: mokshya736@gmail.com
}

lodine is an important element needed for production of thyroid hormone. Almost one-third of the world's population lives in areas of iodine deficiency where the prevalence can be as high as $80 \% .^{2}$ Populations at particular risk live in mountainous areas in SouthEast Asia, Latin America and Central Africa and it is 10 times more common in women than in men $^{3}$.

Nepal lies in an iodine deficiency belt where goiter is endemic and the prevalenceof THD varies from $30.87 \%$

Submitted: $25^{\text {th }}$ August 2018

Accepted: $23^{\text {rd }}$ December 2018

Published: $31^{\text {st }}$ March 2019

\section{How to cite this article}

Sijapati KS, Rijal A, Agrawal S, Khadka DK, Maskey R. Cutaneous manifestations of thyroid hormone disorder. Nepal Journal of Dermatology Venereology and Leprology. 2019;17(1):42-8. doi: http://dx.doi.org/10.3126/njdvl.v17i1.23217

\section{(c) (i)}

Licensed under CC BY 4.0 International License which permits use, distribution and reproduction in any medium, provided the original work is properly cited. 
(hypothyroidism-17.19\% \& hyperthyroidism-13.68\%) to $33.4 \%$ in eastern and western region respectively. ${ }^{4,5}$

Some dermatological findings and diseases may be the first symptoms of thyroid diseasesbut there is no available data on cutaneous manifestations of THD till date. Therefore this study had been planned to identify cutaneous manifestations of THD and to evaluate dermatological manifestations specific for THD.

\section{Materials and Methods}

This is a case control study where all consecutive patients attending the endocrinology clinic of Internal Medicine Department at B.P Koirala Institute of Health Science (BPKIHS), Dharan with a diagnosis of THD were included. As a control group, age and sex matched individuals not having any THD and normal thyroid function test (TFT) were included. Those cases and controls who are not willing to participate in the study were excluded. Ethical approval was taken from Institutional Review committee and Post Graduate protocol committee of BPKIHS prior to conduction of the study (Code number: IRC/536/015).

Informed and written consent was taken from all the patients willing to participate in the study.

The cases and controls were inquired regarding the presence of skin lesions or skin problem or skin changes and if those were present, detail history regarding duration of appearance of skin lesion/ problem/changes, it's mode of onset, site, progression, precipitating factors, h/o atopy, associated systemic symptoms, treatment history and menstrual history were taken. Among the cases, detailed history regarding the duration and type of THD was taken.

A thorough clinical examination i.e. general physical examination, systemic examination \& cutaneous examination regarding site of lesion, type of lesion, number, color, distribution, hair changes, nail changes were carried out in all patients in adequate daylight. Weight and height of the patients were measured while the subjects were wearing light clothing and without shoes. The Body Mass Index (BMI) was calculated by dividing body weight $(\mathrm{kg})$ by the square of the height (m2) and classified according to WHO classification $2004 .^{6}$

Regarding the status of disease, TFT was done in all cases by standard method[MAGLUMI (CLIAchemiluminescence)]and diagnosis was made according to normal reference value. Other relevant investigations were done whenever required.
The final diagnosis of dermatological manifestations was made clinically.

\section{Sample size}

A total of 76 diagnosed patients with THD were enrolled considering the prevalence of cutaneous manifestation $38.9 \%$ in THD byPuri $\mathrm{N}$ with power $80 \%$ and alpha error $5 \%$ and 26 ( 3 cases: 1 control) age and sex matched controls were enrolled. ${ }^{7}$

\section{Statistical analysis}

All the collected data were entered in MS Excel 2007 and converted into Statistical Package for Social Science (SPSS) version 11.5 for statistical analysis. Frequencies \& percentages were calculated for categorical variables. Mean \& standard deviation was calculated for continuous variables. Different graphical methods like bar, subdivided bar, pie chart, were constructed to explore the characteristics of variables.

For inferential statistics, significance of association between THD \& selected variables were examined using chi-square test and independent t-test. If the expected cell count is less than 5 then fisher's exact test was applied. The odds ratio (OR) and 95\% confidence interval $(\mathrm{Cl})$ for association between dermatological manifestations and different types of THD was analysed using logistic regression.

Probability of significance was set at $5 \%$ level.

\section{Results}

Total of 76 cases and 26 controls were analysed in this study. The mean age of cases and controls were $39.6 \pm 12.4$ years and $39.3 \pm 12.4$ years respectively. Majority of the population in the study were female in both cases and controls groups (90.8\% vs $92.3 \%$ ). Similarly most of the cases and controls followed Hindu religion and were from Sunsari district of Nepal (Table 1). In this study, mean BMI of cases and controls were $25.5 \pm 4.6$ and $25.3 \pm 2.9$ respectively, with overweight observed in 42 (55.3) cases and 13 (50.0) controls.

Demographic characteristics of the study population is depicted in the table 1.

Skin changes were seen in 55(72.3\%) cases and 4 (15.4) controls. This was found to be statistically significant (OR-14.4; 95\% Cl 4.43-46.78 and $p<0.001$ ). Hair changes were observed in 21 (27.6\%) cases and 5 $(19.2 \%)$ controls and nail changes in $10(13.2 \%)$ cases and 1 (3.8) controls but no significant association 
was found between THD and hair and nail changes. Table 2 depicts skin, hair and nail changes in cases and controls.

Associated diseases were seen in 53 (69.7\%) cases and $7(26.9 \%)$ controls. This was found to be statistically significant $(\mathrm{OR}=6.25 ; 95 \% \mathrm{Cl} 2.31-16.92$ and $\mathrm{p}$ value $<0.001$.Skin conditions commonly associated were melasma, present in 28 (52.8\%) cases, urticaria in 5 (9.4\%) cases and alopecia areata in 1 (1.9\%) case.

In bivariate analysis, there was significant association between skin changes, skin lesion and skin problem with THD (Table 3). But in multivariate analysis, skin changes and skin problem were significantly associated with THD in our study (Table 4).
Among the THD, subclinical hypothyroidism 46(60.5\%) was most common followed by overt hypothyroidism $21(27.6 \%)$ and overt hyperthyroidism 9(11.8\%). Dermatological manifestations (skin, hair and nail changes) were more common in hypothyroidism.

Skin changes were present in $38(82.6 \%)$ cases with subclinical hypothyroidism, 13(61.9\%) cases with overt hypothyroidism and 4(44.4) cases with overt hyperthyroidism. This was found to be statistically significant $(p=0.029)$. Coarse thick skin was significantly associated with subclinical hypothyroidism $(p<0.001)$ compared to overt hypothyroidism and overt hyperthyroidism.Among hair changes, fine hair was significantly associated with hypothyroidism thanin hyperthyroidism with $\mathrm{p}$ value of 0.014 (table 5).Table 5 shows dermatological manifestations specific for THD and their association with THD.

Table 1: Demographic characteristics of study subjects.

\begin{tabular}{|c|c|c|c|}
\hline Variables & $\begin{array}{c}\text { THD }(n=76) \\
\text { no. }(\%)\end{array}$ & $\begin{array}{c}\text { No THD }(n=26) \\
\text { no. }(\%)\end{array}$ & p-value \\
\hline Age (year) Mean \pm Standard deviation & $39.6 \pm 12.4$ & $39.3 \pm 12.4$ & 0.90 \\
\hline \multicolumn{4}{|l|}{ Gender } \\
\hline Male & $7(9.2)$ & $2(7.7)$ & 0.81 \\
\hline Female & $69(90.8)$ & $24(92.3)$ & \\
\hline \multicolumn{4}{|l|}{ Occupation } \\
\hline Housewives & $26(34.2)$ & $14(53.8)$ & 0.07 \\
\hline Service holders & $50(65.8)$ & $12(46.2)$ & \\
\hline Others (Students, Farmers and Business) & $0(0.0)$ & $0(0.0)$ & \\
\hline \multicolumn{4}{|l|}{ Religion } \\
\hline Hindu & $72(94.7)$ & $25(96.2)$ & 0.77 \\
\hline Others (Kirati and Budhist) & $4(5.3)$ & $1(3.8)$ & \\
\hline \multicolumn{4}{|l|}{ Address } \\
\hline Sunsari district & $62(81.6)$ & $24(92.3)$ & 0.19 \\
\hline Others & $14(18.4)$ & $2(7.7)$ & \\
\hline Body Mass Index (Mean \pm SD) & $25.5 \pm 4.6$ & $25.3 \pm 2.9$ & \\
\hline Normal & $34(44.7)$ & $13(50.0)$ & 0.64 \\
\hline Over weight & $42(55.3)$ & $13(50.0)$ & \\
\hline
\end{tabular}

Note: THD (Thyroid Hormone Disorder as case), No THD (No Thyroid Hormone Disorder as Control)

Table 2: Observed skin, hair and nail changes in study subjects.

\begin{tabular}{|l|c|c|}
\hline Variables & $\begin{array}{c}\text { THD (n=76) } \\
\text { no. (\%) }\end{array}$ & $\begin{array}{c}\text { No THD (n=26) } \\
\text { no. (\%) }\end{array}$ \\
\hline Skin changes observed* & $55(72.3)$ & $4(15.4)$ \\
\hline Xerosis & $32(58.1)$ & $3(75.0)$ \\
\hline Pruritus & $32(58.1)$ & $0(0.0)$ \\
\hline Coarse thick skin & $9(16.36)$ & $0(0.0)$ \\
\hline Fissured feet & $6(10.9)$ & $0(0.0)$ \\
\hline Pale skin & $3(5.4)$ & $0(0.0)$ \\
\hline $\begin{array}{l}\text { Others (hyperhydrosis, hypohydrosis, yellow skin, periorbital } \\
\text { hyperpigmentation) }\end{array}$ & $4(7.2)$ & $0(0.0)$ \\
\hline
\end{tabular}


Table 2 cont ...

\begin{tabular}{|c|c|c|}
\hline Hair changes observed* & $21(27.6)$ & $5(19.2)$ \\
\hline Diffuse scalp hair loss & $14(66.7)$ & $0(0.0)$ \\
\hline Fine hair & $14(66.7)$ & $2(40.0)$ \\
\hline Smooth hair & $8(38.1)$ & $2(40.0)$ \\
\hline Coarse hair & $5(23.8)$ & $0(0.0)$ \\
\hline Others (sparse hair, patchy hair loss) & $4(19.1)$ & $1(20.0)$ \\
\hline Nail changes observed* & $10(13.2)$ & $1(3.8)$ \\
\hline Nail plate changes ${ }^{*}$ & $5(50.0)$ & $1(100.0)$ \\
\hline - Discolored nail plate & $4(40.0)$ & $1(100.0)$ \\
\hline - Vertical striations & $3(30.0)$ & $0(0.0)$ \\
\hline - Thick nail plate & $3(30.0)$ & $1(100.0)$ \\
\hline - Dull nail plate & $3(30.0)$ & $1(100.0)$ \\
\hline - Others (brittle nail plate, thin nail plate, distal onycholysis) & $3(30.0)$ & $0(0.0)$ \\
\hline Subungual hyperkeratosis & $3(30.0)$ & $0(0.0)$ \\
\hline Absence of cuticle & $1(10.0)$ & $0(0.0)$ \\
\hline Obliterated lunula & $1(10.0)$ & $0(0.0)$ \\
\hline
\end{tabular}

*Individual patients had more than one dermatological changes

Table 3: Factors associated with thyroid hormone disorders in a bi-variate model.

\begin{tabular}{|c|c|c|c|c|}
\hline \multirow[b]{2}{*}{ Factors } & \multicolumn{2}{|c|}{ Number exposed } & \multirow[b]{2}{*}{ OR (95\% Cl) } & \multirow[b]{2}{*}{ P-value } \\
\hline & $\begin{array}{c}\text { THD (\%)* } \\
(n=76)\end{array}$ & $\begin{array}{c}\text { No THD (\%)* } \\
\quad(n=26)\end{array}$ & & \\
\hline Overweight & $42(55.3)$ & $13(50.0)$ & $1.23(0.51-3.01)$ & 0.64 \\
\hline Skin problems & $53(69.7)$ & $6(23.1)$ & $7.68(2.72-21.62)$ & $<0.001$ \\
\hline Skin lesions & $58(76.3)$ & $7(26.9)$ & $8.74(3.16-24.13)$ & $<0.001$ \\
\hline Skin changes & $55(72.3)$ & $4(15.4)$ & $14.4(4.43-46.78)$ & $<0.001$ \\
\hline Hair changes & $21(27.6)$ & $5(19.2)$ & $1.60(0.53-4.81)$ & 0.39 \\
\hline Nail changes & $10(13.2)$ & $1(3.8)$ & $3.78(0.46-31.13)$ & 0.18 \\
\hline Associated diseases & $53(69.7)$ & $7(26.9)$ & $6.25(2.31-16.92)$ & $<0.001$ \\
\hline
\end{tabular}

*Proportion (\%) unless specified otherwise, THD(Thyroid Hormone Disorder), No THD (No Thyroid Hormone Disorder), OR (Odds ratio), $\mathrm{Cl}$ (Confidence interval)

Table 4: Factors associated with THD in a Multi-variate model.

\begin{tabular}{|c|c|c|}
\hline Factors & Adjusted OR (95\% CI) & P-value \\
\hline Skin changes & $8.9(2.56-30.98)$ & 0.001 \\
\hline Skin problem & $3.5(1.12-11.30)$ & 0.03 \\
\hline
\end{tabular}

*Proportion (\%) unless specified otherwise OR (Odds ratio), $\mathrm{Cl}$ (Confidence interval)

Table 5: Association between dermatological manifestations with thyroid hormone disorders ( $N=76)$

\begin{tabular}{|l|c|c|c|c|}
\hline Dermatological changes & $\begin{array}{c}\text { Subclinical } \\
\text { hypothyroidism, } \\
(\mathbf{N}=\mathbf{4 6 )} \mathbf{n}(\mathbf{\%})\end{array}$ & $\begin{array}{c}\text { Overt } \\
\text { hypothyroidism, } \\
(\mathbf{N}=\mathbf{2 1}) \mathbf{n}(\%)\end{array}$ & $\begin{array}{c}\text { Overt } \\
\text { hyperthyroidism, } \\
(\mathbf{N}=\mathbf{9}) \mathbf{n}(\%)\end{array}$ & P-value \\
\hline Skin changes & $38(82.6)$ & $13(61.9)$ & $4(44.4)$ & 0.029 \\
\hline Xerosis & $18(39.1)$ & $11(52.4)$ & $3(33.3)$ & 0.787 \\
\hline Pruritus & $18(39.1)$ & $11(52.4)$ & $3(33.3)$ & 0.787 \\
\hline Coarse thick skin & $21(45.6)$ & $2(9.5)$ & $3(33.3)$ & $<0.001$ \\
\hline Fissured feet & $3(6.5)$ & $3(14.3)$ & $0(0.0)$ & 0.469 \\
\hline $\begin{array}{l}\text { Others (hyperhydrosis, pale skin, } \\
\text { periorbitalhypermelanosis, hypohydrosisetc,) }\end{array}$ & $7(10.44)$ & $0(0.0)$ & $0(0.0)$ & - \\
\hline
\end{tabular}


Table 5 cont ...

\begin{tabular}{|c|c|c|c|c|}
\hline Hair changes & $12(26.1)$ & $7(33.3)$ & $2(22.2)$ & 0.768 \\
\hline Diffuse hair loss & $8(17.4)$ & $5(23.8)$ & $2(22.2)$ & 0.071 \\
\hline Fine hair & $19(41.3)$ & $4(19.1)$ & $1(11.1)$ & 0.014 \\
\hline Smooth hair & $6(13.1)$ & $2(9.5)$ & $0(0.0)$ & - \\
\hline Coarse hair & $5(10.8)$ & $3(14.3)$ & $1(11.1)$ & 0.260 \\
\hline Sparse hair & $3(6.5)$ & $1(4.7)$ & $0(0.0)$ & 0.269 \\
\hline Nail changes & $8(17.4)$ & $2(9.5)$ & $0(0.0)$ & 0.21 \\
\hline Nail plate changes & $5(10.8)$ & $0(0.0)$ & $(0.0)$ & - \\
\hline - Discoloration & $4(8.6)$ & $0(0.0)$ & $0(0.0)$ & - \\
\hline - Striations & $3(6.5)$ & $0(0.0)$ & $0(0.0)$ & - \\
\hline - Thick \& dull nail plate & $3(6.5)$ & $0(0.0)$ & $0(0.0)$ & - \\
\hline $\begin{array}{l}\text { - Others (brittle nail plate, thin nail plate, } \\
\text { distal onycholysis) }\end{array}$ & $3(6.5)$ & $0(0.0)$ & $0(0.0)$ & - \\
\hline Subungual hyperkeratosis & $3(6.5)$ & $0(0.0)$ & $0(0.0)$ & - \\
\hline Loss of cuticle & $1(2.1)$ & $0(0.0)$ & $0(0.0)$ & - \\
\hline Obliterated lunula & $1(2.1)$ & $0(0.0)$ & $0(0.0)$ & - \\
\hline Skin problems & 34 (73.9) & $15(71.4)$ & $4(44.4)$ & $<0.001$ \\
\hline Skin lesions & $36(78.3)$ & 17 (80.9) & $5(55.5)$ & $<0.001$ \\
\hline Associated skin diseases & $36(78.3)$ & 13 (61.9) & $4(44.4)$ & $<0.001$ \\
\hline
\end{tabular}

\section{Discussion}

The clinical manifestations of THD are often first seen in the skin where thyroid hormone plays an integral role in sustaining natural function of skin. Thyroid hormone directly influences proteoglycan synthesis in the skin by stimulating fibroblasts. In addition, it plays a regulatory role in epidermal differentiation. As a result, the skin presents important external markers associated with thyroid disease that can signal dermatologists to investigate and diagnose thyroid disorder. $^{8}$

Hypothyroidism (88.1\%) was the most common THD followed by hyperthyroidism (11.8\%). Similarly, dermatological manifestations (skin, hair and nail changes) were more common in hypothyroidism. This could be because the overall prevalence of hypothyroidism is higher than hyperthyroidism. ${ }^{3}$

More than half of the cases $(72.3 \%)$ had skin changes of them predominant skin changes were xerosis (58.1\%) and pruritus $(58.1 \%)$ followed by coarse thick skin (16.36\%) and fissured feet(10.9\%) which were more frequently seen in hypothyroidism. Dryness together with itching of skin is due to diminished eccrine and sebaceous gland activity in hypothyroidism. ${ }^{9}$ These results were in corroboration with study conducted by Keen MA et al in which xerosis was most common cutaneous sign of hypothyroidism observed in $57.17 \%$ of patients. ${ }^{10}$ Coarse thick skin and fissured feet can be explained by diminished keratinocyte levels of plasminogen which is involved in corneocyte shedding process, disturbed development of the lamellar granules and decreased epidermal sterol synthesis. ${ }^{11}$ Pale skin, yellow skin and hypohydrosiswere observed less frequently which corresponds to study by Khurram $\mathrm{IM}$ et al and Jabbour SA et al. ${ }^{12,13}$ These findings are due to reflex vasoconstriction as a compensatory mechanism to diminished core temperature because of decreased basal metabolic rate in hypothyroidism; increased deposition of water and mucopolysaccharide (chondroitin sulphate and hyaluronic acid) in dermis, elevation of serum and tissue carotene concentration and cytological changes in eccrine apparatus respectively.

Hair changes were present in almost one fourth (27.6\%) of cases. Of them majority (66.7\%) had diffuse hair loss over scalp, which is comparable to study by Dograet alwherethey found diffuse hair loss (40.62\%) as the most common hair change in hypothyroidism. ${ }^{14}$ Disturbed hair cycle (inhibition of initiation and shortened duration of anagen phase) leads to increase percentage of hair in telogen phase leading to telogen effluvium . Other hair changes were coarse scalp hair (23.8\%) due to diminished sebum secretion and sparse hair (19\%). In contrast to study by Rosen T et al,where fine hair and smooth hair (soft and silky) were 
seen more in hypothyroidism than hyperthyroidism. ${ }^{15}$ It could be because all the cases were under treatment for THD which might have helped in improving the texture of hair strand.

Nail changes (13.2\%) were the third most common dermatological manifestation. Among nail changes, nail plate changes were most common and loss of cuticle were least common finding, similar to study by Jamwal $A$ et al. ${ }^{16}$ Nail plate changes such as thick nail plate is due to obscuration of nail bed vasculature as a result of reflex peripheral vasoconstriction in hypothyroidism, dull nail plate is because of alteration in normal cellular and intercellular organization and brittle nails were due to decreased nail matrix function as a result of decreased level of thyroid hormones. Likewise, vertical striations over nail plates are contributed by normal aging process and deficiency of minerals such as calcium.

Skin changes were statistically significant $(p=0.001)$ with THD while hair changes and nail changes were not statistically significant which could be because of small sample size.

In our study, associated diseases were present in more than half $(69.7 \%)$ of the cases. Of them melasma $(52.8 \%)$ was most common followed by urticaria (9.4\%). Melasma was found to be associated with

\section{References}

1. Niepomnisczhe $H$, Amad RH. Skin disorders and thyroid diseases. J Endocrinol Invest. 2001; 24:628-38. https://doi.org/10.1007/BF03343905

2. Zimmerman MB. lodine deficiency. Endocr Rev. 2009; 30:376-408. https://doi.org/10.1210/ er.2009-0011

3. Vanderpump MPJ. The epidemiology of thyroid diseases. In: Braverman LE, Utiger RD (eds). Werner and Ingbar's The Thyroid: A Fundamental and Clinical Text, 9th edition. JB Lippincott-Raven: Philadelphia. 2005. p.398-496.

4. Baral N, Lamsal M and Koner BC. Thyroid dysfunction in eastern Nepal. South Asian J. Trop. Med. Public Health. 2002; 33: 638-41

5. Mittal A, Sathian B, Kumar A, Chandrasekharan $\mathrm{N}$, Dwedi S. The Clinical Implications of Thyroid Hormones and its Association with Lipid Profile: A Comparative Study from Western Nepal, Nepal J Epidemiol. 2010; 1(1):11-6.
THD with $p$ value of 0.012 . This association has been well documented by Luftiet al in their study, further Fitzpatrick skin type 3 and 4 of our patient may contribute to melasma. ${ }^{17}$ Regarding urticaria, our finding is almost comparable to study done by Leznoff and Sussman where they found patients with chronic idiopathic urticaria have evidence of thyroid disorder. ${ }^{18}$ Other associated diseases were onychomycosis, atopic dermatitis, seborrhoeic keratosis, lichen simplex chronicus, verruca vulgaris, tinea infection, seborrhoiec dermatitis, pompholyx, periorbitalhypermelanosis, achrochordon, pityriasisversicolor and pitted keratolysis. These findings might be coincidental.

\section{Conclusion}

This study revealed that among the THD, prevalence of hypothyroidism is higher in study population and is closely associated with skin, hair and nail changes such as xerosis, coarse thick skin, fissured feet, diffuse hairloss and thick/dull nailplates. These skin, hair and nails changes may go unrecognized and most of the times are not investigated properly. Thus, patients presenting with such signs and symptoms should be investigated properly to rule out any underlying THD so that patients get curative rather than symptomatic treatment.

Financial disclosure: None.

Conflict of interest to disclosure: None declared.

6. Appropriate body-mass index for Asian populations and its implications for policy and intervention strategies. WHO expert consultation. Lancet 2004; 363: 157-63. https://doi. org/10.1016/S0140-6736(03)15268-3

7. Puri N. A study on cutaneous manifestations of thyroid disease. Indian J Dermatol 2012;57:247-8. https://doi.org/10.4103/0019-5154.96227

8. Doshi DN, Blyumin ML, Kimball AB. Cutaneous manifestations of thyroid disease, clinics in dermatology. 2008; 26:283-7.

9. Means MA, Dobson RL. Cytological changes in the sweat gland in hypothyroidism. JAMA. 1963; 186:113. https://doi.org/10.1001/ jama.1963.03710020033007

10. Keen MA, Hassan I, Bhat MH. A Clinical study of cutaneous manifestation of Hypothyroidism Indian J Dermatol. 2013; 58:326-32.

11. Isseroff RR, Chun KT, Rosenberg RM. Triiodothyronine alters the cornification of 
cultured human keratinocytes. B J Invest Derm. 1989; 120:503- 10 . https://doi. org/10.1111/j.1365-2133.1989.tb01323.x

12. Khurram IM, Choudhary KS, Khan M, Islam N. Clinical presentation of hypothyroidism: a case control analysis. Journal of Ayub Medical College Abottabad 2003; 15: 1-6.

13. Jabbour SA, Miller JL. Endocrinopathiesand the skin. Int J Dermatol. 2000; 39: 88-99. https://doi. org/10.1046/j.1365-4362.2000.00874.x

14. Dogra A, Dua A, Singh P. Thyroid and skin. Indian J Dermatol. 2006; 51:96-9. https://doi. org/10.4103/0019-5154.26927

15. Rosen T, Kleman GA, Jorizzo JL. Thyroid and the skin. In: Callen JP, Jorizzo JL, eds. Dermatological Signs of Internal Disease, 3rd edn. Philadelphia: Saunders. 2003.p. 175-9.
16. Jamwal A, Sharma A, Rather PA. Cutaneous manifestation of hypothyroidism: prospective hospital based study. J Adv Med Dent Scie. 2013; 1(2):5-12.

17. Lufti RJ, Fridmanis $M$, Misiunas $A L$, Pafume $O$, Gonzalez EA, Villemur JA, et al. Association of melasma with thyroid autoimmunity and other thyroidal abnormalities and their relationship to the origin of melasma. J Clin Endocrinol Metabol. 1985; 61:28-31. https://doi.org/10.1210/jcem$61-1-28$

18. Leznoff A. and Sussman GL. Syndrome of idiopathic urticarial and angioedema with thyroid autoimmunity: A study of 90 patients. J Allergy Clinlmmunol. 1989; 84:66-7. https://doi. org/10.1016/0091-6749(89)90180-2 